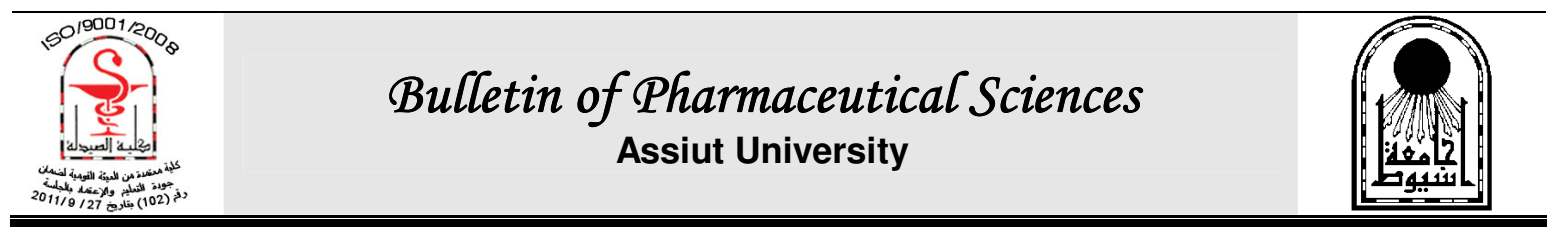

\title{
MUCOADHESIVE POLYMERS AS EFFICIENT DRUG DELIVERY SYSTEMS
}

\author{
Gamal El-Din A. El-Gindy, Mona M. El-Mahdy, Ghareb M. Soliman* and Abeer S. Hassan \\ Department of Pharmaceutics, Faculty of Pharmacy, Assiut University, Assiut, Egypt
}

\begin{abstract}
The drug action can be reinforced as a result of the development of new drug delivery systems. Over the past few decades, mucosal drug delivery has received a great deal of attention to improve both the local and systemic drug effects. Drug delivery across the mucosa bypasses the first-pass hepatic metabolism and avoids the degradation caused by the gastrointestinal enzymes. Mucoadhesive dosage forms are designed to enable prolonged retention at the desirable site of action, provide sustained release of drug and thus, lead to an improved bioavailability, as well as therapeutic outcomes. Compared with other mucosal tissues, vaginal mucosal cavity is more appropriate and attractive for drug delivery. In addition, a prolonged contact of mucoadhesive dosage forms with the vaginal mucosa may be achieved more easily than at other absorption sites like rectum or intestinal mucosa. This review aims to highlight the recent advances in the study of mucoadhesion and mucoadhesive polymers. It provides an overview of the structure of mucosal membranes, the mechanism and theories involved in mucoadhesion, and finally it describes briefly the main characteristics and the advantages of vaginal mucoadhesive drug delivery systems compared with other delivery systems.
\end{abstract}

\section{INTRODUCTION}

Generally, the term adhesion can be defined as the molecular force of attraction in the area of contact between unlike bodies that acts to hold them together for extended periods of time ${ }^{1}$. When adhesion occurs in a biological tissue, it is often termed bioadhesion. Furthermore if this adhesion occurs on mucosal membranes it is termed mucoadhesion ${ }^{2}$.

Mucosal membranes are the moist surfaces lining the walls of various body cavities. Also, they provide lubrication and wettability of the epithelial surface of the cell, and regulate its moisture content ${ }^{3}$. Therefore, mucoadhesion can be defined as attractive interaction at the interface between a pharmaceutical dosage form and a mucosal membrane $^{2}$.

Mucoadhesion has been widely promoted as a way of achieving site specific drug delivery for extended period of time with a consequent enhancement of bioavailability through the incorporation of mucoadhesive hydrophilic polymers within pharmaceutical formulations along with the active drug candidates $^{4 \& 5}$. The objective of designing these systems is to maximize the therapeutic effect and provide uniform drug delivery ${ }^{6}$. A great attention has been focused on development of mucoadhesive drug delivery systems. One of the first applications of mucoadhesive formulations dates back to $1947^{6}$.

Advantages associated with the use of mucoadhesives in drug delivery system

The use of mucoadhesive polymers for improving drug delivery has been of interest for several years owing to several important invitro and in-vivo advantages as follows ${ }^{5 \& 7}$ :

- The intimate contact between mucoadhesive formulations and mucus membrane results in high effective drug concentration and localized drug release in desirable regions and hence, enhancement of the clinical efficacy of drugs in these regions such as

Received in 21/6/2015 \& Accepted in 17/12/2015 
nasal cavity, eye, mouth, stomach, intestine, and vagina ${ }^{8}$.

- On using some mucoadhesive polymers, the drug permeability through mucosal tissues or membranes may be increased as a result of the modification of the tight junctions between the cells and thus, facilitate the absorption of macromolecules such as peptides and proteins ${ }^{9}$.

- The interaction between mucoadhesive formulations and mucosal surface offers the potential to prolong the residence time of the dosage form at the site of application, thereby, reduces administration frequency and increases patient compliance ${ }^{10}$.

- The avoidance of first pass metabolism, simplifies the administration of a dosage form and promotes local or systemic effects $^{7 \& 9}$.

- Additionally, significant cost reductions may be achieved and dose related side effects may be reduced due to drug localization at the diseased sites.

\section{Mucus and mucosal layer}

Bioadhesive formulations are mainly administered at the mucous membrane, which is responsible for attachment to mucoadhesive drug delivery systems ${ }^{9}$. Mucosal membranes of human are relatively permeable and allow fast drug absorption ${ }^{11}$. There membranes are characterized by an epithelial layer which is covered by mucus to moist their surfaces. The mucus is secreted by goblet cells in single layered epithelia, whereas multi-layered epithelia contain specialized glands that can secrete mucus onto the epithelial surface ${ }^{12}$. The exact composition of the mucus layer differs significantly depending on the species, the anatomical location and pathological states ${ }^{13}$.

Mucus gel is mainly a translucent complex and viscid lubricating secretion which forms a thin continuous gel adheres to mucosal epithelial surface ${ }^{14}$. Mucus contains mucin glycoproteins, lipids, inorganic salts and 95\% water by mass making it a highly hydrated system. The most important glycoprotein of mucus is mucin, which is responsible for its structure. The mucin glycoproteins (Fig.1) are high molecular weight proteins (molecular mass 2-14 X $10^{6}$ Dalton) possessing attached oligosaccharide units ${ }^{15}$. It has been shown that there are several types of mucins in vaginal fluid, saliva, tears and also within the gastrointestinal tract ${ }^{10}$.

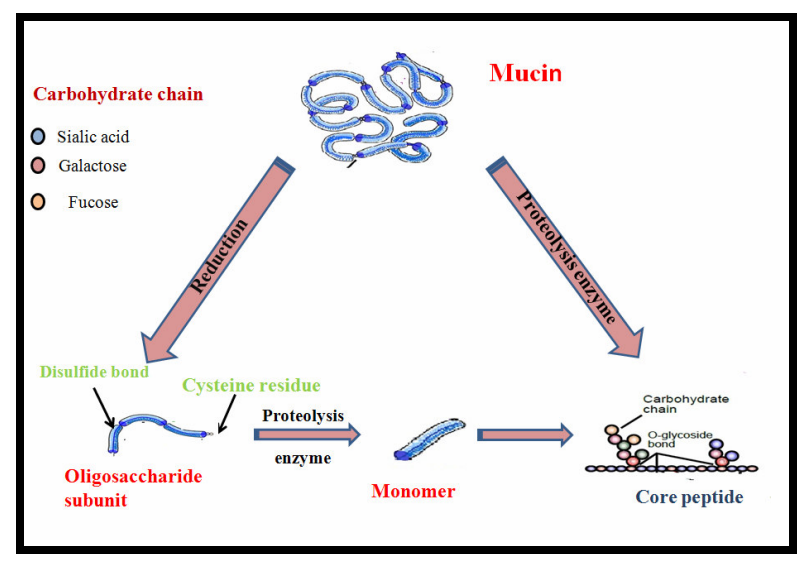

Fig. 1: Polymeric structure of mucin molecules.

\section{Mechanism of mucoadhesion}

Adhesion is an interfacial phenomenon which is affected by surface energies. When an adhesive bond is formed between two materials, the surface free energy of the system is diminished, degrading two free surfaces and creating a new interface ${ }^{16}$. The mucoadhesive substance should be spread over the mucosal membrane to initiate close contact, promoting the diffusion of its chains within the mucus. Each step can be facilitated by the nature of the dosage form and how it is administered. So, the mechanism of mucoadhesion is generally divided in to two stages, the contact stage and the consolidation stage (Fig. 2).

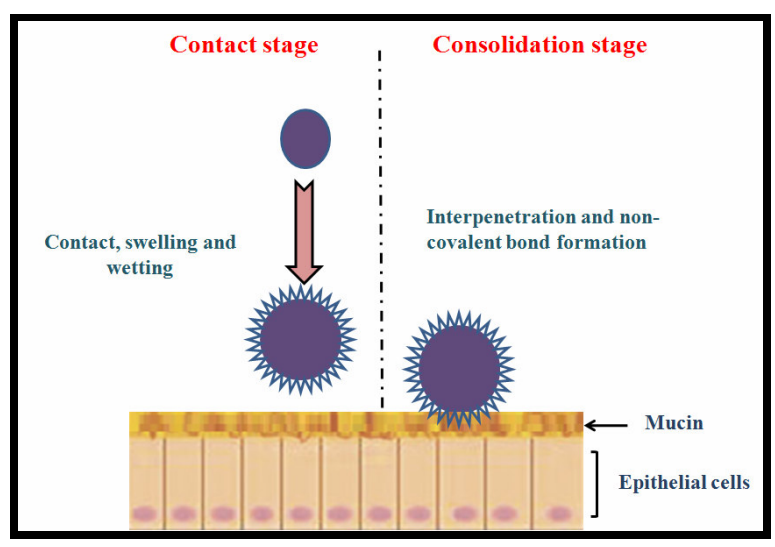

Fig. 2: Steps of mucoadhesion. 


\section{Contact stage}

This stage is characterized by the contact between the mucoadhesive and the mucous membrane, with wetting and swelling of the formulation when the polymer spreads over the surface of mucosal membrane. This initiates deep contact with the mucus layer and allows mucoadhesives to adhere to the mucosal membrane by the surface tension and also the forces that exist at site of contact ${ }^{17}$.

\section{Consolidation stage}

The consolidation stage is explained by two theories: the diffusion theory and the dehydration theory. According to diffusion theory, the mucoadhesive polymer molecules and the glycoproteins of the mucus gel mutually interact by means of interpenetration of their chains to create the area of contact and build up of secondary type of bonds such as van der Waal forces and hydrogen bonds. The bond strength depends on the degree of penetration between two polymeic group ${ }^{18}$. The mucoadhesive formulation must have features favoring both chemical and mechanical interactions. For example, molecules with hydrogen bonds forming groups $(-\mathrm{OH},-$ $\mathrm{COOH}$ ), with an anionic surface charge, high molecular weight, flexible chains and surfaceactive properties can possess mucoadhesive properties ${ }^{1}$.

\section{Theories of mucoadhesion}

There are several general theories that have been used to explain mucoadhesion phenomena:

\section{1- The electronic theory}

This theory suggests that the electrostatic forces are critical in the formation of bond adhesions. It is applicable when the mucoadhesive polymer and the mucus have different electronic characteristics and transfer of electrons occurs resulting in formation of electrical double layer and electrostatic attraction at the interface ${ }^{6 \& 10}$, where the attractive forces within this electronic double layer determine the mucoadhesive strength ${ }^{1}$. The electrostatic interactions between the mucus layer containing negatively charged mucin and positively charged chitosan are considered the reason for its good adhesion on the mucosal surfaces ${ }^{10}$. In addition to the electrostatic forces there are other possible contributing factors to its mucoadhesivness, such as its wettability, entanglement and possible interactions with the mucin.

\section{2- The adsorption theory}

Several surface interactions that result in adhesion include primary and secondary bond formation. This theory considers that the attraction between the mucus and the mucoadhesive polymers is achieved via these primary and secondary bonds such as hydrogen bonds and van der Waals forces. Hydrophobic effects may also play an important role especially when the mucoadhesive polymers have an amphiphilic nature. Also, these secondary bonds are more desirable and important criterion for drug delivery system, resulting in semi permanent interactions ${ }^{9 \& 10}$.

\section{3- Wetting theory}

Wetting theory applies to liquid mucoadhesive formulations which present the affinity of mucoadhesive polymer to the surface of mucosal tissue in order to spread over it. The contact angle can be used as a measuring technique for this affinity. To provide adequate spreadability with excellent mucoadhesion, the contact angle must be equal or close to zero ${ }^{9 \& 19}$.

\section{4- Diffusion theory}

Diffusion theory assumes the formation of interpenetration layer as a result of the penetration of mucoadhesive macromolecule into the mucus gel and diffusion of soluble mucin into dosage form ${ }^{19}$. This process is dependent on the molecular weight of mucoadhesive macromolecules, their hydrodynamic size and mobility. Also, the depth of interpenetration depends on the diffusion coefficient and the time of contact ${ }^{20}$.

\section{5- Fracture theory}

Fracture theory attributes the difficulty of separation of two surfaces after adhesion to the adhesive bond strength. Also, the adhesive bond strength is known as the fracture strength. According to this theory, the force required to separate the solid mucoadhesive from the mucus membrane can be calculated ${ }^{10 \& 21}$. 


\section{6- Mechanical theory}

Mechanical theory considers the effect of surface roughness. Also, it explains the adhesion between mucoadhesive liquid and a rough surface or a surface rich in pores ${ }^{22 \& 23}$. The theory essentially suggests that the adhesion between the two substrates is due to mechanical interlocking of the adhesive into the irregularities and micro-cracks on a rough surface ${ }^{9 \& 24}$.

\section{Mucoadhesive polymers}

Tsuneji $\mathrm{N}$ et al. reported the first study which presented the use of mucoadhesive material ${ }^{25}$. The author proposed an improved treatment for stomatitis by using adhesive tablets. Mucoadhesive polymers are often included in the formulation to increase the retention time on the mucosal tissue. On exposure to moisture the polymers form swellable networks, attached by cross-linking agents and readily adhere to the surfaces. These polymers possess optimal polarity and fluidity that permits the mutual adsorption and interpenetration of polymer molecule and mucus to take place ${ }^{4}$.

There are three regions in which the adhesive bond between a polymer and mucus gel can be formed ${ }^{26 \& 27}$

1- The surface of the bioadhesive polymer.

2-The interfacial layer between the bioadhesive polymer and mucosa.

3- The mucosal surface.

An ideal polymer for mucoadhesive drug delivery systems should have the following characteristics

- The polymer and its degradation products should be nontoxic, nonabsorbable and nonirritant ${ }^{28}$.

- The polymer preferably form a strong noncovalent bond with the mucus or epithelial cell surface and adhere quickly to moist tissue in order to possess some site specificity without any change in the physical property of the delivery system ${ }^{9}$.

- In addition, the polymer must show bioadhesive properties in both dry and liquid state as well as inhibit the enzymes present at the site of action and enhance the penetration of the active drug molecule ${ }^{12 \& 14}$.

\section{Other characteristics}

- The polymer should have optimum molecular weight and should allow easy incorporation of the drug ${ }^{29}$.

- The polymer must not decompose on storage or during the shelf life of the dosage form ${ }^{12}$.

- The polymer must be easily available and its cost should not be high.

- The polymer should have good spreadability, wetting, swelling, solubility and biodegradability properties ${ }^{30}$.

- The $\mathrm{pH}$ of the polymer solution should not be too acidic or too basic ${ }^{30}$.

- The polymer should be sufficiently crosslinked but not to the degree of suppression of bond forming groups ${ }^{9}$.

\section{Classification of polymers ${ }^{12}$}

Mucoadhesive polymers can be categorized into natural and synthetic polymers. Synthetic polymers such as cellulose derivatives, polyacrylate and polyhydroxyethyl methylacrylate, whereas sodium alginate, guar gum and chitosan are considered as natural polymers $^{31}$.

\section{Anionic polymers}

Anionic polymers have been extensively used for designing mucoadhesive delivery systems due to their ability to exhibit strong hydrogen bonding with the mucin on mucosal membrane ${ }^{32}$. Carboxyl groups are able to form hydrogen bonds with hydroxyl groups of oligosaccharide side chains present in the mucosal layer. Carbonic acid and sulphonate groups are mainly responsible for the adhesion of anionic polymers to mucus gel layer ${ }^{33}$. Disadvantages of these polymers are their incompatibility with multivalent cations. In presence of such cations, these polymers precipitate leading to a strong reduction in their adhesive properties ${ }^{34}$. Moreover, the swelling of these polymers is $\mathrm{pH}$ dependant, at higher $\mathrm{pH}$, adhesion properties of polymers are reduced due to the higher swelling ${ }^{12}$. Examples of these polymers are given in table 1 . 
Table 1: Commonly used mucoadhesive polymers classified according to their charge ${ }^{35}$.

\begin{tabular}{||c|c||}
\hline Types & Most common polymers \\
\hline \multirow{3}{*}{ Anionic polymers } & Carbopol $^{\circledR}$ \\
\cline { 2 - 2 } & Polycarbophil $^{\circledR}$ \\
\cline { 2 - 2 } & $\begin{array}{c}\text { Sodium } \\
\text { carboxymethylcellulose }^{\circledR}\end{array}$ \\
\hline Cationic polymers & Chitosan \\
\hline \multirow{4}{*}{ Non ionic polymers } & $\begin{array}{c}\text { Hydroxypropylcellulose } \\
\text { Methylcellulose }\end{array}$ \\
\cline { 2 - 2 } & Polyethylene glycol \\
\cline { 2 - 2 } & Hydroxyethylcellulose \\
\hline
\end{tabular}

\section{Cationic polymers}

These polymers have a strong bioadhesion because of ionic interactions between polymers and anionic groups such as sialic acid moieties of mucosal membrane. For instance, chitosan is the most important polymer of this group because it has permeation enhancing properties and available for a cheap price ${ }^{36 \& 37}$.

\section{Non ionic polymers}

The adhesion of these polymers is caused by the interpenetration of the polymer and mucin chains. This is followed by the entanglement of their chains. In general, the polymers are less adhesive than cationic and anionic polymers. Their adhesive properties are not $\mathrm{pH}$ dependent ${ }^{12}$.

\section{Amphoteric polymers}

These polymers have both anionic and cationic properties. The most common amphoteric polymers that are used in mucoadhesive formulations are gelatin and $\mathrm{N}$ carboxymethylchitosan ${ }^{6}$. Gelatin was reported to exhibit relatively poor mucoadhesive properties due to its amphoteric nature and self-neutralization of both cationic and anionic charges within its structure ${ }^{38 \& 39}$. Thanou et al.$^{40}$ used $\mathrm{N}$-carboxymethylchitosan to enhance the intestinal absorption of low molecular weight heparin across intestinal epithelia both in-vitro and in-vivo. However, in the study reported by DiColo et al. ${ }^{41}$ the same polymer failed to show any enhanced intraocular penetration of ofloxacin. Therefore, the combination of both anionic and cationic properties leads to the reduction of mucoadhesive properties as compared to single charged polymers ${ }^{42}$.

\section{Thiolated polymers}

Free thiol groups in the polymeric skeleton are responsible for the formation of disulphide bonds with that of the cysteine rich subdomains present in mucin. This can improve the mucoadhesive properties of the polymers (e.g. poly (acrylic acid) and chitosan $)^{43-47}$. Various thiolated polymers including chitosan-iminothiolane, poly(acrylic acid)-cysteine, chitosan-thioglycolic acid, alginate-cysteine, poly(methacrylic acid)cysteine and sodium carboxymethylcellulosecysteine have been prepared and used in drug delivery systems ${ }^{5}$.

\section{Examples of commonly used bioadhesive polymers 1- Carbopol/carbomer $(\mathrm{Cp})^{48 \& 49}$}

Carbopol/carbomer (carboxy polymethylene) is a synthetic, high molecular weight, cross linked polymer of acrylic acid copolymerized with allyl sucrose. The carboxy groups provided by the acrylic acid back bone of the polymer are responsible for many of the product characteristics. Carbopol has average molecular weight ranges from $1 \times 10^{6}$ to $4 \times 10^{6}$ Dalton. They are soluble in water, alcohol and glycerine. The $\mathrm{pH}$ of $1 \%$ aqueous solution ranges from 2.5 to 3 .

Carbopols 934P, 971P and 974P are the only pharmaceutical grades of the resin intended for internal use. Carbopol 934P is a high molecular weight polymer of acrylic acid cross-linked with allyl ethers of sucrose and polymerized in benzene.

Carbopol 974P is polymerized in ethyl acetate and slightly treated with potassium base. It is a new and safer analogue of carbopol 934P.

Advantages: Carbopol is an excellent thickening, emulsifying, suspending, gelling agent and common component in bioadhesive dosage forms. Also, it exhibits unique gelation behavior, which can be easily triggered by changes in solution $\mathrm{pH}^{6}$.

Lin and Sung ${ }^{50}$ used carbopol $934 \mathrm{P}$ as a mucoadhesive polymer with pluronic to prepare pilocarpine hydrochloride in-situ gelling formulation for ocular drug delivery which may be instilled into the eye as a liquid which forms a gel sticking to ocular mucosal surface and provides an improved dosage form 
retention. The authors demonstrated that the carbopol / pluronic solution mixture may be reproducibly administered into the eye as drops and form strong gel following the phase transition. Both the in-vitro and in-vivo results indicated that the combined polymer systems performed better in retaining drugs. Therefore, this system can be used as in-situ gelling vehicle for ophthalmic drug delivery.

\section{2- Chitosan (CS)}

Chitosan is a natural cationic copolymer consisting of glucosamine and N-acetyl glucosamine units. It is a hydrolyzed polysaccharide mostly obtained by alkalinization of $\mathrm{N}$-deacetylation of chitin derived from the shells of crustaceans ${ }^{51}$. It is the second most widely used polymer next to cellulose $^{52}$. It provides an excellent example of a cationic polyelectrolyte due to its good biocompatibility, neither toxicity nor biodegradable properties ${ }^{53}$. In addition, it exhibits widely accepted mucoadhesive properties due to the presence of $\mathrm{OH}$ and $\mathrm{NH}_{2}$ groups together with its cationic character that can give rise to hydrogen bonding and electrostatic interactions between cationic primary amino groups and anionic moieties of the mucin chain ${ }^{52}$.

M. W. Joraholmen et al. ${ }^{54}$ found that chitosan coated liposomes for topical vaginal therapy showed prolonged release of incorporated clotrimazole. Chitosan was selected as mucoadhesive polymer both to prolong retention of system at the vaginal site and act on biofilms responsible for high recurrence of infections. The ex-vivo penetration experiments performed on the pregnant sheep vaginal tissue showed that chitosan coated liposomes assured increased clotrimazole tissue retention and reduced its penetration as compared to the control. The authors concluded that chitosan-coated liposomes have been optimized to assure localized and safe vaginal therapy of clotrimazole.

\section{3- Sodium alginate ( $\mathrm{Na}$ Alg.)}

$\mathrm{Na} \mathrm{Alg.} \mathrm{is} \mathrm{a} \mathrm{natural} \mathrm{polysaccharide}$ polymer extracted from brown sea weed by the use of dilute alkali. The polymer mainly consists of sodium salt of alginic acid, a polyuronic acid composed of $\beta$-D-mannuronic acid residues. Chemically it is an anionic copolymer of 1, 4-linked-D-mannuronic acid and $\mathrm{L}$-guluronic acid. The $\mathrm{pH}$ of $1 \%$ aqueous solution is 7.2. It is slowly soluble in water forming a viscous, colloidal solution. It is insoluble in alcohol and in hydroalcoholic solutions in which the alcohol content is greater than $30 \%$ by weight ${ }^{55 \& 56}$.

Choi et al. ${ }^{57}$ investigated the release of omeprazole from the buccal adhesive tablets composed of sodium alginate and hydroxy propyl methylcellulose. The results obtained showed that the omeprazole buccal adhesive tablet would be useful to deliver omeprazole which undergoes hepatic first pass metabolism following oral administration.

\section{4- Hydroxy propyl methylcellulose (HPMC)}

HPMC is a hydrophilic mucoadhesive polymer. It is mixed cellulosic ether and may be regarded as propylene glycol ether of methylcellulose. Its molecular weight is approximately 86,000 Dalton. This polymer is soluble in cold water, forming a viscous colloidal solution, insoluble in alcohol, ether and chloroform but soluble in mixture of methyl alcohol and methylene chloride. Also, it is stable in dry conditions ${ }^{49 \& 58}$. Furthermore, on using HPMC in vaginal mucoadhesive delivery systems, it can retain the drug in vaginal tract for a few days without any toxic effects or physiological modifications, prolonging its residence time on the vaginal mucosa ${ }^{29}$.

\section{5- Boronate-containing copolymers (BCCs)}

BCCs are water soluble mucoadhesive polymers. They are synthesized by the copolymerization of 3-aminophenylboronic acid (APBA) precursors. They showed specific polysaccharide binding capacity and formed insoluble complexes with mucin due to the interactions between boronate and oligosaccharides in mucin chains. This unique interaction can be used to develop new techniques for the targeting to specific tumeoral cells ${ }^{59}$.

\section{Mucoadhesive drug delivery systems}

The mucosal layer lines a number of tissues such as gastrointestinal tract(GI), airways, ear, nose, vagina, rectum and eye. These systems represent specific sites for attachment of any bioadhesive material. The 
mucoadhesive drug delivery systems include the following ${ }^{60}$ :

1- Buccal delivery systems,

2- Oral delivery systems,

3- Vaginal delivery systems,

4- Rectal delivery systems,

5- Nasal delivery systems and Ocular delivery systems.

\section{1- Oral mucoadhesive drug delivery systems}

Absorption of drug via the mucous membranes of the oral cavity can be achieved in the sublingual, buccal, or local regions. Different regions of the oral cavity differ greatly in terms of their composition as well as their suitability for drug delivery. The thin and highly permeable membrane of the sublingual tissue is considered as a perfect target for rapid absroption into the systemic circulation due to the large surface area and high blood flow to this region. An application of a bioadhesive formulation for local drug delivery can increase the contact time with the epithelium. For instance, alginate shows a high retention time on esophageal tissue, being a potential drug delivery vehicle can provide a barrier to protect the underlying epithelium from gastric reflux ${ }^{61}$.

Akiyama et al $^{62}$ studied the comparison between adhesive furosemide microspheres with non adhesive microspheres administered orally to human. The authors showed that higher furosemide plasma concentrations and an increased absorption were achieved with adhesive microspheres compared to nonadhesive ones.

\section{2-Ocular mucoadhesive drug delivery systems \\ The conventional ophthalmic dosage} forms such as aqueous solution and ointments have low ocular bioavailability (2-10\%). This is attributed to the small area for penetration, the presence of the lipophilic corneal epithelium as an absorption barrier and the short contact time ${ }^{63}$. From a $50 \mu 1$ drop applied to the eye approximately $20-30 \mu 1$ is lost from overflow and another $2 \mu \mathrm{l}$ per blink is lost continuously $^{64}$. Recently, Mansour et al. ${ }^{65}$ developed poloxamer-based in-situ gelling formulations of ciprofloxacin hydrochloride which showed controlled release, mucoadhesive properties due to the addition of hydroxypropylmethyl cellulose (HPMC) or hydroxyethyl cellulose (HEC) and also showed improved ocular bioavailability compared with conventional marketed eye drops.

\section{3- Nasal mucoadhesive drug delivery system}

The nose is considered as a region for local and systemic drug delivery because of the large surface area and thin, porous and highly vascularized nasal epithelium which achieve high absorption as well as rapid transport of the absorbed substances directly into systemic blood circulation, thus avoiding hepatic first pass metabolism ${ }^{66}$. The nasal route can be used as an ideal alternative to the parenterals for administering drugs intended for systemic effect $^{8 \& 66}$. Furthermore, the enzymatic activity of the nasal epithelium is lower than that of the GI tract and therefore, higher bioavailability of active pharmaceutical ingredients such as peptides and proteins can be achieved ${ }^{67}$.

Dyer et al. ${ }^{68}$ showed that the most effective formulation for nasal insulin absorption is a chitosan powder delivery system, which was found to be better than chitosan nanoparticles and chitosan solution formulations, respectively.

\section{4-Buccal mucoadhesive drug delivery system}

Buccal drug delivery can achieve two different therapeutic aims: either local or systemic therapy. The buccal mucosa has a number of advantages in comparison with other routes of drug administration. It has a rich blood supply that flows directly into the jugular vein and thereby is protecting the drug from first pass metabolism of the liver and degradation in the GI tract by enzymes ${ }^{69}$. Therefore, higher bioavailability of the drugs with lower adverse effects can be achieved.

Ramana et al. ${ }^{70}$ developed mucoadhesive buccal tablets of metoprolol tartarate with the objective of avoiding first pass metabolism and prolonging duration of action using carbopol 934P, hydroxypropylmethyl cellulose, hydroxyethyl cellulose and sodium carboxymethyl cellulose. The best mucoadhesive performance and in-vitro drug release profile were exhibited by the tablet containing hydroxyethyl cellulose and carbopol 934P in a ratio of $1: 2$. 


\section{5- Vaginal mucoadhesive drug delivery system}

\section{Physiology and anatomy of vagina}

Human vagina is often described as slightly a S-shaped fibromuscular tube between 6 and $10 \mathrm{~cm}$ long connecting the uterus to the outer surface of the body. The wall of vagina consists of three layers: the epithelial layer, the muscular coat and the tunica adventia ${ }^{71}$. Drugs absorbed from the vagina does not undergo first pass hepatic metabolism since the blood leaving the vagina enters the peripheral circulation. Women of reproductive age secret fluid at a rate of 3-4 gram / hour ${ }^{72}$.

\section{Vaginal mucosa as a site for drug delivery}

The vagina is an important organ of reproductive tract, in addition to being genital organ with functions related to conception, it serves as a suitable route for drug administration $^{73}$. Vaginal drug delivery systems are commonly used to provide local therapy for administration of locally acting drugs such as antifungals, antiprotozoals, labor inducing agent, proteins and antiviral ${ }^{74}$. Furthermore, the vaginal route is considered as an alternative route for systemic administration because of its rich blood supply and the large surface area ${ }^{75}$.

Besides avoiding the hepatic first pass metabolism and reducing the GI and hepatic side effects, a high permeability to a wide range of drug molecules including peptides and proteins can be achieved by using the vaginal route $^{76}$. Also, it has the possibility for uterine targeting of active agents such as progesterone which produces its effect on the uterus and is highly metabolized when administered orally ${ }^{77}$. The plasma concentrations of vaginally administered progesterone were found to be higher in the uterine artery than in the radial artery, indicating a preferential distribution of progesterone to the uterus. This confirmed the existence of direct local transport from the vagina to the uterus, termed the first uterine pass effect $^{78}$. Moreover, the vaginal route offers a favorable alternative to the parenteral route for some drugs such as bromocriptine ${ }^{79}$, oxytocin ${ }^{80}$, calcitonin, human growth hormone and steroids used for replacement therapy or contraception $^{63}$.

Despite all the advantages of vaginal route, the changes of membrane during the menstrual cycles and postmenopausal should be taken into account. The reduced epithelial thickness in postmenopausal women may change the rate of drug absorption ${ }^{29}$. In addition, the currently available vaginal delivery systems (e.g., solutions, creams, suppositories and gels) have numerous limitations such as leakage, messiness and low residence time, which cause poor patient compliance.

Several attempts are being made to formulate novel vaginal drug delivery systems containing bioadhesive polymers that can extend the residence time of the drug on the vaginal mucosa. This could enhance therapeutic efficacy of the drug and improve patient compliance ${ }^{81 \& 82}$.

Robinson and Bologna. ${ }^{81}$ used mucoadhesive gel based on polycarbophil to provide prolonged vaginal residence time (3-4 days) of progesterone and therefore, improve its therapeutic efficacy.

Cevher et $a l .{ }^{83}$ used mucoadhesive gel of clomiphene citrate with carbomers and their thiolated derivatives for the treatment of infections. The results obtained showed higher treatment efficiency as well as prolonged residence time at application site with lower dose.

Alam M. et al. ${ }^{84}$ prepared an acidbuffering bioadhesive vaginal clotrimazole (antifungal) and metronidazole (antiprotozoal and antibacterial) tablets for the treatment of genitourinary tract infections. The authors found that polycarbophil and sodium carboxymethyl cellulose were good combinations for an acid buffering bioadhesive vaginal tablet. From ex-vivo retention studies, it was found that the bioadhesive polymers retain the tablet for more than $24 \mathrm{hr}$ inside the vaginal cavity.

\section{Conclusions}

Mucoadhesion is an important strategy to prolong the residence time of drug delivery systems at the site of administration, as well as to improve the patient compliance. It has been widely used to achieve both local and systemic actions of drug candidates. Several theories have been suggested to explain mucoadhesion. The formulation of mucoadhesive drug delivery systems depends on the selection of a suitable polymer with good mucoadhesion 
properties and biocompatibility. Currently, many investigators have focused their studies on the vaginal mucoadhesive dosage forms, which have numerous advantages over traditional oral dosage forms such as, avoidance of first pass hepatic metabolism, improved bioavailability of drugs and enhancement of patient compliance. The permeability and properties of the vaginal cavity are suitable for placement of a mucoadhesive dosage form in order to obtain controlled and/or sustained delivery of therapeutic agents. Systematic disease treatment via transmucosal drug delivery from the vaginal cavity continues to be studied using a variety of dosage forms containing mucoadhesive polymers. Finally, mucoadhesive drug delivery systems present a promising future in improving therapeutic drug action.

\section{REFERENCES}

1- E. Mathiowitz, D. E. Chickering III and C.-M. Lehr, "Bioadhesive Drug Delivery Systems: Fundamentals, Novel Approaches, and Development", CRC Press. (1999).

2- I. Henriksen, K. L. Green, J. D. Smart, G. Smistad and J. Karlsen, "Bioadhesion of hydrated chitosans: An in-vitro and invivo study", Int. J. Pharm., 145 (1), 231240 (1996).

3- C. Marriott, N. Gregory, V. Lenaerts and R. Gurny, "Mucus Physiology and Pathology", In: "Bioadhesive Drug Delivery Systems", Boca Raton, 1990, pp. 1-24.

4- K. Chowdary and L. Srinivas, "Mucoadhesive drug delivery systems: A review of current status", Ind. Drug. Bomb., 37 (9), 400-406 (2000).

5- G. P. Andrews, T. P. Laverty and D. S. Jones, "Mucoadhesive polymeric platforms for controlled drug delivery", Eur. J. Pharm. Biopharm., 71 (3), 505518 (2009).

6- V. V. Khutoryanskiy, "Advances in mucoadhesion and mucoadhesive polymers", Macromol. Biosci., 11 (6), 748-764 (2011).

7- J. Woodley, "Bioadhesion", Clin. Pharmacokinet., 40 (2), 77-84 (2001).
8- J. W. Lee, J. H. Park and J. R. Robinson, "Bioadhesive-based dosage forms: The next generation", J. Pharm. Sci., 89 (7), 850-866 (2000).

9- F. C. Carvalho, M. L. Bruschi, R. C. Evangelista and M. P. D. Gremião, "Mucoadhesive drug delivery systems", Braz. J. Pharm. Sci., 46 (1), 1-17 (2010).

10- T. Yu, G. P. Andrews and D. S. Jones. "Mucoadhesion and Characterization of Mucoadhesive Properties, in Mucosal Delivery of Biopharmaceuticals", Springer, 2014, pp. 35-58.

11- J. Cleary, L. Bromberg and E. Magner, "Adhesion of polyether-modified poly (acrylic acid) to mucin", Langmuir, 20 (22), 9755-9762 (2004).

12- J. Hombach and A. Bernkop-Schnürch, "Mucoadhesive Drug Delivery Systems", In: "Drug Delivery", Springer, 2010, pp. 251-266.

13- X. Zhu, D. Zhou, S. Guan, P. Zhang, Z. Zhang and Y. Huang, "Preparation and characterization of novel multi-core chitosan microspheres for stomachspecific delivery of hydrophilic antibiotics", J. Mat. Sci. Materials in Medicine, 23 (4), 983-990 (2012).

14- M. Jimenez-Castellanos, H. Zia and C. T. Rhodes, "Mucoadhesive drug delivery systems", Drug Dev. Ind. Pharm., 19, 143-194 (1993).

15- C. Marriott and N. Gregory, "Mucus Physiology and Pathology", In: "Bioadhesive Drug Delivery Systems", CRC Press Boca Raton, FL., 1990, pp. 123.

16- S. A. Mortazavi, B. G. Carpenter, and J. D. Smart, "A comparative study on the role played by mucus glycoproteins in the rheological behaviour of the mucoadhesive/mucosal interface", Int. $\boldsymbol{J}$. Pharm., 9 (14), 195-201 (1993).

17- H. Hägerström, K. Edsman and $M$. Strømme, "Low frequency dielectric spectroscopy as a tool for studying the compatibility between pharmaceutical gels and mucous tissue", J. Pharm. Sci., 92 (9), 1869-1881 (2003).

18- J. D. Smart, "The basics and underlying mechanisms of mucoadhesion", Adv. Drug Deliver. Rev., 57 (11), 1556-1568 (2005). 
19- N. A. Peppas and P. A. Buri, "Surface, interfacial and molecular aspects of polymer bioadhesion on soft tissues", $\boldsymbol{J}$. Control. Release, 2, 257-275 (1985).

20- M. Subirade and L. Chen, "Delivery and Controlled Release of Bioactives in Foods and Neutraceuticals, Food-ProteinDerived Materials and Their Use as Carriers and Delivery Systems for Active Food Components", 2008, Cambridge, England: Woodhead Publishing Ltd.

21- G. Ponchel, F. Touchard, D. Duchêne and N. A. Peppas, "Bioadhesive analysis of controlled-release systems. I. Fracture and interpenetration analysis in poly (acrylic acid)-containing systems", J. Control. Release, 5 (2), 129-141 (1987).

22- N. A. Peppas and J. J. Sahlin, "Hydrogels as mucoadhesive and bioadhesive materials: A review", Biomaterials, 17 (16), 1553-1561 (1996).

23- D. Packham, "The mechanical theory of adhesion-A seventy year perspective and its current status", in First International Congress on Adhesion Science and Technology (1998).

24- A. Kinloch, "The science of adhesion", $\boldsymbol{J}$. Mater. Sci., 17 (3), 617-651 (1982).

25- N. Tsuneji, N. Yuji, N. Naoki, S. Yoshiki and S. Kunio, "Powder dosage form of insulin for nasal administration", $\boldsymbol{J}$. Control. Release, 1 (1), 15-22 (1984).

26- S. Mortazavi, B. Carpenter and J. Smart, "A comparative study on the role played by mucus glycoproteins in the rheological behaviour of the mucoadhesive/mucosal interface", Int. J. Pharm., 94 (1), 195-201 (1993).

27- K. Park and J. R. Robinson, "Bioadhesive polymers as platforms for oral-controlled drug delivery: Method to study bioadhesion", ibid., 19 (2), 107-127 (1984).

28- A. Khar and R. K. J. Ali, "Mucoadhesive drug delivery systems", Drug Dev. Ind. Pharm., 23. 489-515 (1997).

29- C. Valenta, "The use of mucoadhesive polymers in vaginal delivery", Adv. Drug Deliver. Rev., 57 (11). 1692-1712.(2005).

30- G. P. A.a. D. S. J. Tao Yu, "Mucoadhesion and Characterization of Mucoadhesive Properties", Hand Book of Mucosal Delivery of Biopharmaceuticals Springer
Science Business Media NewYork, Vol. 2, 2014, pp. 35-57.

31- T. M. R. S. K. Tilloo and V.V. Kale, "Mucoadhesive microparticulate drug delivery system", Int. J. Pharm., 9, 52-56 (2011).

32- S. Roy, K. Pal, A. Anis, K. Pramanik and B. Prabhakar, "Polymers in mucoadhesive drug-delivery systems: A brief note", Des. Monomers Polym., 12 (6), 483-495 (2009).

33- S. Rossi, M. Bonferoni, F. Ferrari and C. Caramella, "Drug release and washability of mucoadhesive gels based on sodium carboxymethylcellulose and polyacrylic acid", Pharm. Dev. Tech., 4 (1), 55-63 (1999).

34- C. Valenta, B. Christen and BernkopSchnÜrch, "Chitosan-EDTA conjugate: A novel polymer for topical gel", J. Pharm. Pharmacol., 50 (5), 445-452 (1998)

35- J. Das Neves and M. Bahia, "Gels as vaginal drug delivery systems", Int. J. Pharm., 318 (1), 1-14 (2006).

36- P. Artursson, T. Lindmark, S. S. Davis and L. Illum, "Effect of chitosan on the permeability of monolayers of intestinal epithelial cells (Caco-2)", Pharm. Res., 11, 1358-1361 (1994).

37- H. Leuben, C. Rentel, A. Kotze, C. Lehr, A. de Boer, J. Verhoef and H. Junginger, "Mucoadhesive polymers in peroral peptide delivery. IV. Polycarbophil and CS are potent enhancers of peptide transport across intestinal mucosae invitro", J. Control. Release, 45, 15-23 (1997).

38- T. Okano, "Biorelated Polymers and Gels", Academic, New York (1998).

39- J. Wang, Y. Tabata, D. Bi and K. Morimoto, "Evaluation of gastric mucoadhesive properties of aminated gelatin microspheres", J. Control. Release, 73 (2), 223-231 (2001).

40- M. Thanou, M. Nihot, M. Jansen, J. C. Verhoef and $\mathrm{H}$. Junginger, "Mono $\mathrm{N}$ carboxymethyl chitosan (MCC), a polyampholytic chitosan derivative, enhances the intestinal absorption of low molecular weight heparin across intestinal epithelia in-vitro and in-vivo", J. Pharm. Sci., 90 (1), 38-46 (2001). 
41- G. Di Colo, Y. Zambito, S. Burgalassi, I. Nardini and M. Saettone, "Effect of chitosan and of $\mathrm{N}$-carboxymethylchitosan on intraocular penetration of topically applied ofloxacin", Int. J. Pharm., 273 (1), 37-44 (2004).

42- H. L. Lueßen, B. J. de Leeuw, M. W. Langemeÿer, A. B. G. de Boer, J. C. Verhoef and H. E. Junginger, "Mucoadhesive polymers in peroral peptide drug delivery. VI. Carbomer and chitosan improve the intestinal absorption of the peptide drug buserelin in-vivo", Pharm. Res., 13 (11), 1668-1672 (1996).

43- P. Lim Soo, L. Luo, D. Maysinger and A. Eisenberg, "Incorporation and release of hydrophobic probes in biocompatible polycaprolactone-block-poly (ethylene oxide) micelles: Implications for drug delivery", Langmuir., 18 (25), 999610004 (2002).

44- R. Savić, L. Luo, A. Eisenberg and D. Maysinger, "Micellar nanocontainers distribute to defined cytoplasmic organelles", Science, 300 (5619), 615-618 (2003).

45- C. Allen, D. Maysinger and A. Eisenberg, "Nano-engineering block copolymer aggregates for drug delivery", Colloid Surface B., 16 (1), 3-27 (1999).

46- C. E. Kast, D. Guggi, N. Langoth and A. Bernkop-Schnürch, "Development and invivo evaluation of an oral delivery system for low molecular weight heparin based on thiolated polycarbophil", Pharm. Res., 20 (6), 931-936 (2003).

47- C. Tuleu, M. Newton, J. Rose, D. Euler, R. Saklatvala, A. Clarke and S. Booth, "Comparative bioavailability study in dogs of a self emulsifying formulation of progesterone presented in a pellet and liquid form compared with an aqueous suspension of progesterone", J. Pharm. Sci., 93 (6), 1495-1502 (2004).

48- H. S. Ch'Ng, H. Park, P. Kelly and J. R. Robinson, "Bioadhesive polymers as platforms for oral controlled drug delivery II: Synthesis and evaluation of some swelling, water insoluble bioadhesive polymers", ibid., 74 (4), 399-405 (1985).

49- WadeA. "Hand Book of Pharmaceutical Excipients", American Pharmaceutical
Association Publication, Washington, DC (1986).

50- H. R. Lin and K. Sung, "Carbopol / pluronic phase change solutions for ophthalmic drug delivery", J. Control. Release, 69 (3), 379-388 (2000).

51- M. C. A. K. Singla, "Chitosan: Some pharmaceutical and biological aspects - an update", J. Pharm. Pharmacol., 53, 10471167 (2001).

52- B. Andreas and D. Sarah, "Chitosan-based drug delivery systems", Eur. J. Pharm. Biopharm., 81, 463-469 (2012).

53- A. Portero, D. Teijeiro-Osorio, M. J. Alonso and C. Remuñán-López, "Development of chitosan sponges for buccal administration of insulin", Carbohyd. Polym., 68 (4), 617-625 (2007).

54- M. W. Joraholmen, Z. Vanic, I. Tho and N. Skalko-Basnet, "Chitosan-coated liposomes for topical vaginal therapy: Assuring localized drug effect", Int. J. Pharm., 472 (1-2), 94-101 (2014).

55- F. F. C. M. J. Martín-Villenaa, A. C. Calpena-Campmanyb, N. Bozal-de Febrerc, M. A. Ruiz-Martíneza and B. Clares, "NaverosaNovel microparticulate systems for the vaginal delivery of nystatin: Development and characterization", Carbohyd. Polym., 94, 1-11 (2013).

56- T. F. Duchene and N. A. Peppas, "Pharmaceutical and medical aspects of bioadhesive systems for drug adminstration", Drug Dev. Ind. Pharm., 14 (2-3), 283-318 (1998).

57- H. G. Choi, J. H. Jung, C. S. Yong, C. D. Rhee, M. K. Lee, J. H. Han, K. M. Park and C. K. Kim, "Formulation and in-vivo evaluation of omeprazole buccal adhesive tablet", J. Control. Release, 68 (3). 405412 (2000).

58- K. v. a. B. G. S., "Chemically modifted cellilosic polymers", Drug Dev. Ind. Pharm., 19 (1-2), 1-13 (1993).

59- A. Sosnik, J. das Neves and B. Sarmento, "Mucoadhesive polymers in the design of nano-drug delivery systems for administration by non-parenteral routes: A review", Prog. Polym. Sci., 39 (12), 20302075 (2014). 
60- R. Khanna, S. Agarwal and A. Ahuja, "Mucoadhesive buccal drug delivery: A potential alternative to conventional therapy", Ind. J. Pharm. Sci., 60 (1), 1 (1998).

61- H. Batchelor, M. Tang, P. Dettmar, F. Hampson, I. Jolliffe and D. Craig, "Feasibility of a bioadhesive drug delivery system targeted to oesophageal tissue", Eur. J. Pharm. Biopharm., 57 (2), 295298 (2004).

62- Y. Akiyama, N. Nagahara, E. Nara, M. Kitano, S. Iwasa, I. Yamamoto, J. Azuma and Y. Ogawa, "Evaluation of oral mucoadhesive microspheres in man on the basis of the pharmacokinetics of furosemide and riboflavin, compounds with limited gastrointestinal absorption sites", J. Pharm. Pharmacol., 50 (2), 159166 (1998).

63- H. a. A. Juliane, "Mucoadhesive Drug Delivery Systems", Springer Verlag Berlin Heidelberg Handbook of Experimental Pharmacology, Vol. 197, 2010, pp. 252265.

64- D. Maurice and S. Mishima, "Ocular Pharmacokinetics, in Pharmacology of the Eye", Springer, 1984, pp. 19-116.

65- M. Mansour, S. Mansour, N. D. Mortada and S. S. Abd ElHady, "Ocular poloxamer-based ciprofloxacin hydrochloride in-situ forming gels", Drug Dev. Ind. Pharm., 34 (7), 744-752 (2008).

66- M. I. Ugwoke, R. U. Agu, N. Verbeke and R. Kinget, "Nasal mucoadhesive drug delivery: Background, applications, trends and future perspectives", Adv. Drug Deliver. Rev., 57 (11), 1640-1665 (2005).

67- H. Lueßen, C. M. Lehr, C. O. Rentel, A. Noach, A. De Boer, J. Verhoef and H. Junginger, "Bioadhesive polymers for the peroral delivery of peptide drugs", $\boldsymbol{J}$. Control. Release, 29 (3), 329-338 (1994).

68- A. Dyer, M. Hinchcliffe, P. Watts, J. Castile, I. Jabbal-Gill, R. Nankervis, A. Smith and L. Illum, "Nasal delivery of insulin using novel chitosan based formulations: A comparative study in two animal models between simple chitosan formulations and chitosan nanoparticles", Pharm. Res., 19 (7), 998-1008 (2002).

69- H. Park and J. R. Robinson, "Physicochemical properties of water insoluble polymers important to mucin/epithelial adhesion", J. Control. Release, 2, 47-57 (1985).

70- M. Ramana, C. Nagda and M. Himaja, "Design and evaluation of mucoadhesive buccal drug delivery systems containing metoprolol tartrate", Ind. J. Pharm. Sci., 69 (4), 515 (2007).

71- N. Dobaria, R. Mashru and N. Vadia, "Vaginal drug delivery systems: A review of current status", E. Central Afri. J. Pharm. Sci., 10 (1), 3-13 (2008).

72- A. Hussain and F. Ahsan, "The vagina as a route for systemic drug delivery", $\boldsymbol{J}$. Control. Release, 103 (2), 301-313 (2005).

73- E. Baloglu, A. Bernkop-Schnürch, S. Y. Karavana and Z. A. Senyigit, "Strategies to prolong the intravaginal residence time of drug delivery systems", J. Pharm. Pharm. Sci., 12 (3), 312-336 (2009).

74- R. R. de Araújo Pereira and M. L. Bruschi, "Vaginal mucoadhesive drug delivery systems", Drug Dev. Ind. Pharm., 38 (6), 643-652 (2012).

75- K. Vermani and S. Garg, "The scope and potential of vaginal drug delivery", Pharm. Sci. Technol. To., 3 (10), 359-364 (2000).

76- S. Muranishi, A. Yamamoto and $\mathrm{H}$. Okada, "Rectal and Vaginal Absorption of Peptides and Proteins, in Biological Barriers to Protein Delivery", Springer, 1993, pp. 199-227.

77- E. Cicinelli, M. Cignarelli, S. Sabatelli, F. Romano, L. M. Schonauer, R. Padovano and N. Einer-Jensen, "Plasma concentrations of progesterone are higher in the uterine artery than in the radial artery after vaginal administration of micronized progesterone in an oil-based solution to postmenopausal women", Fertil. Steril., 69 (3), 471-473 (1998).

78- D. De Ziegler, C. Bulletti, B. De Monstier and A. Jääskeläinen, "The first uterine pass effect", Ann. N. Y. Acad. Sci., 828, 291-299 (1997).

79- M. Vermesh, G. T. Fossum and O. A. Kletzky, "Vaginal bromocriptine: Pharmacology and effect on serum prolactin in normal women", Obstet. Gynecol., 72 (5), 693-698 (1988). 
80- F. C. Christensen, M. Tehranifar, J. L. Gonzalez, C. R. Qualls, V. J. Rappaport and W. F. Rayburn, "Randomized trial of concurrent oxytocin with a sustainedrelease dinoprostone vaginal insert for labor induction at term", Am. J. Obstet. Gynecol., 186 (1), 61-65 (2002).

81- J. R. Robinson and W. J. Bologna, "Vaginal and reproductive system treatments using a bioadhesive polymer", J. Control. Release, 28 (1), 87-94 (1994).

82- E. Bonucci, P. Ballanti, P. Ramires, J. Richardson and L. Benedetti, "Prevention of ovariectomy osteopenia in rats after vaginal administration of Hyaff 11 microspheres containing salmon calcitonin" Calcif. Tissue Int., 56 (4), 274-279 (1995).
83- E. Cevher, M. Taha, M. Orlu and A. Araman, "Evaluation of mechanical and mucoadhesive properties of clomiphene citrate gel formulations containing carbomers and their thiolated derivatives" Drug Deliv., 15 (1), 57-67 (2008).

84- M. A. Alam, F. J. Ahmed, Z. I. Khan, R. K. Khar and M. Ali, "Development and evaluation of acid-buffering bioadhesive vaginal tablet for mixed vaginal infections", AAPS Pharm. Sci. Tech., 8 (4), 229-236 (2007). 


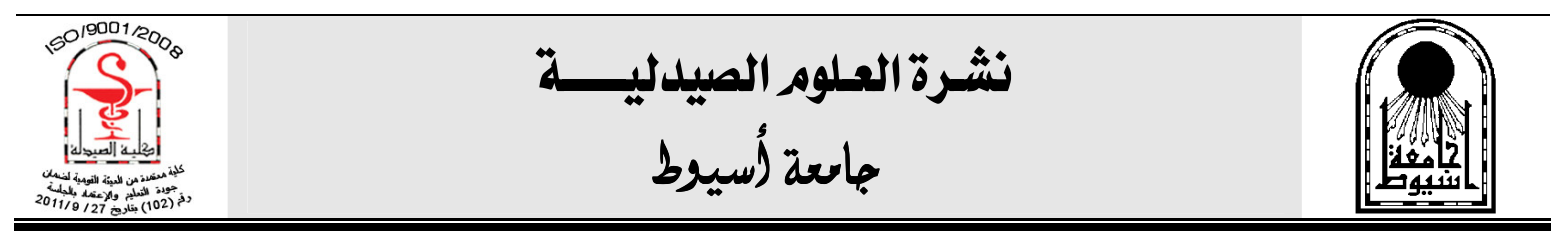

\section{البوليمرات ذات الالتصاق الحيوى المخاطى كانظمه فعاله لتوصيل العقار}

جمال الدين عبد الفتاح الجندي - منى مصطفى المهدى - غريب محمد عبد العال - عبير سعد حسن

\section{قسم الصيدلانيات ، كلية الصيدله ، جامعة أسيوط ، مصر}

التاثير الحيوى للعقار يتم تعزيزه نتيجه لتطوير انظمه جديده لتوصيل العقار . على مدى العقود الإديه

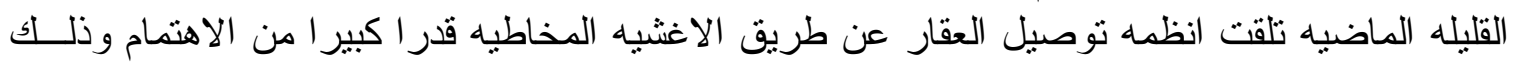

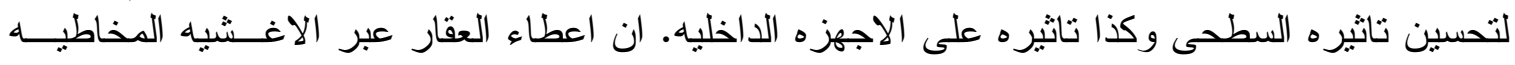

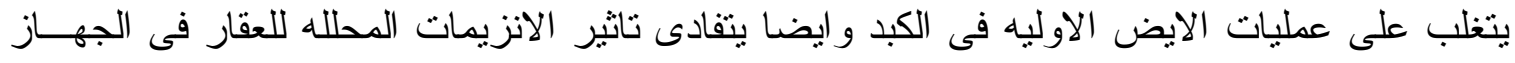

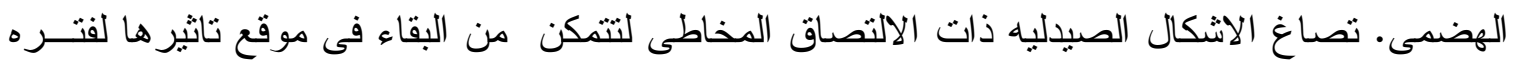

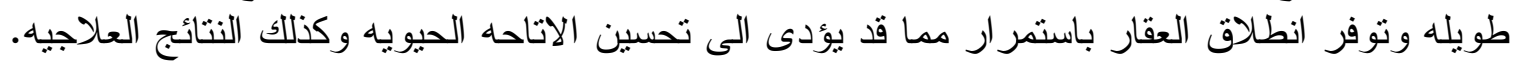

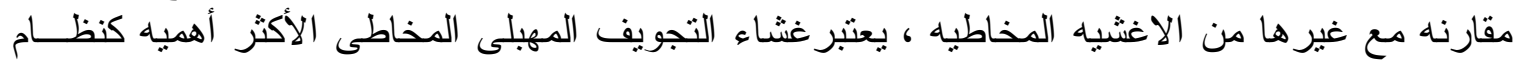

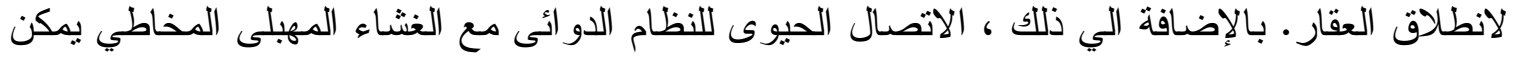

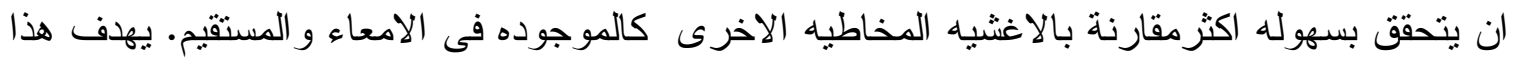

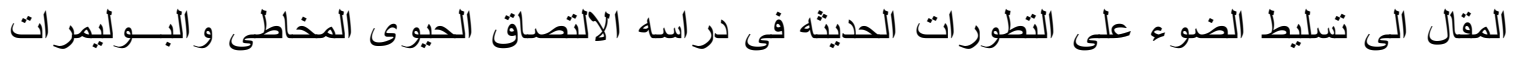

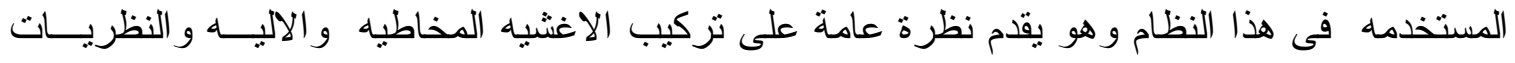

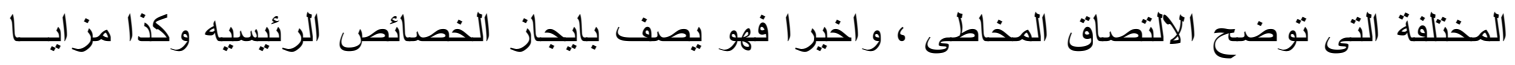

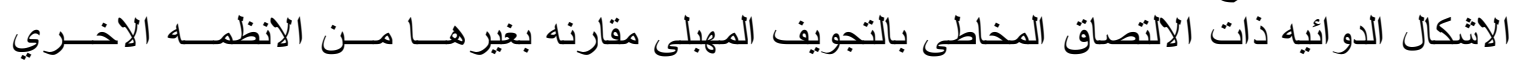
المستخذمة لتتاول العقار . 